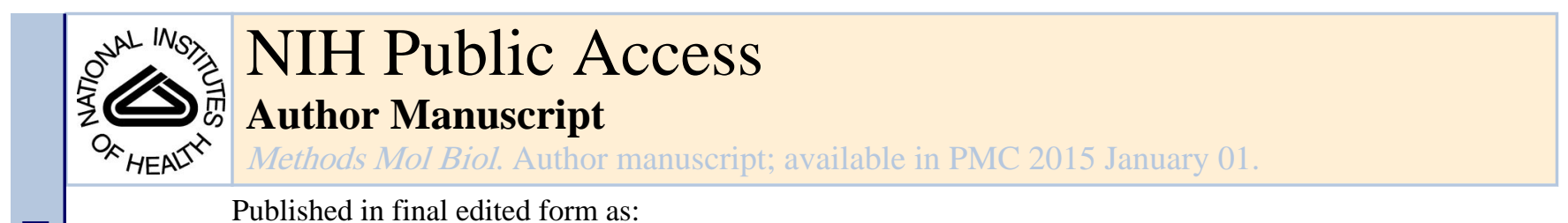

Published in final edited form as:

Methods Mol Biol. 2014 ; 1188: 57-64. doi:10.1007/978-1-4939-1142-4_5.

\title{
Stable Isotope Labeling by Amino Acids in Cultured Primary Neurons
}

\author{
Guoan Zhang ${ }^{1}$, Katrin Deinhardt ${ }^{2}$, and Thomas A. Neubert ${ }^{1}$ \\ ${ }^{1}$ Dept. of Biochemistry and Molecular Pharmacology and Kimmel Center for Molecular Medicine \\ at the Skirball Institute, New York University School of Medicine, New York, NY 10016, USA \\ ${ }^{2}$ Institute for Life Sciences and Centre for Biological Sciences, University of Southampton, Life \\ Sciences Building 85, Southampton, SO17 1BJ, UK
}

\begin{abstract}
Cultured primary neurons are a well-established model for the study of neuronal function. Conventional stable isotope labeling with amino acids in cell culture (SILAC) requires nearly complete metabolic labeling of proteins and therefore is difficult to apply to cultured primary neurons, which do not divide in culture. Here we describe a protocol that utilizes a multiplex SILAC labeling strategy for primary cultured neurons. In this strategy, two different sets of heavy amino acids are used for labeling cells for the different experimental conditions. This allows for straightforward SILAC quantitation using partially labeled cells because the two cell populations are always equally labeled.
\end{abstract}

\section{Keywords}

SILAC; Primary neurons; Mass spectrometry; Proteomics; Quantitation

\section{Introduction}

\begin{abstract}
Stable isotope labeling with amino acids in cell culture (SILAC) involves cell culture in media containing "light" (natural) or "heavy" isotope-containing amino acids (1). It is important to obtain a high degree of label incorporation because incomplete labeling will skew the SILAC ratio in favor of the light protein (2). To ensure nearly complete labeling, it is generally required to maintain cells in SILAC media for at least five cell divisions so that even proteins with zero turnover rate will be highly labeled $(>97 \%)$ by dilution alone $(1,3)$.
\end{abstract}

\footnotetext{
Corresponding author: Thomas A. Neubert, Skirball Institute, New York University School of Medicine, Thomas.Neubert@med.nyu.edu.

12 Although significant label incorporation occurs within only two days of culture (average incorporation > 50\%), longer labeling times are preferred to increase the amount of labeled proteins if permitted by the experimental design. We normally label cells for 10 days, which should result in $>90 \%$ average label incorporation.

${ }^{13}$ We do not recommend labeling time less than 2 days. Low incorporation level will decrease the number of quantifiable proteins. Also, accuracy of quantitation will be compromised due to decreased signal-to-noise ratio and partial overlapping of isotopic distributions between light and medium signals.

${ }^{14}$ Different proteins are labeled at considerably different rates. For example, nuclear proteins such as histones are labeled at much slower rates than typical proteins. After 10 days of labeling, the incorporation is usually around 30-40\% for histones. This needs to be taken into consideration when performing experiments that target slow-turnover proteins.
} 
Primary neurons are widely used as a very important model in neuroscience because in general their functional properties more closely resemble the in vivo state than those of transformed cell cultures. Because the primary neurons do not divide in culture, it is difficult to use the standard light/heavy SILAC labeling because of the issue of incomplete labeling. To overcome this difficulty, a method has been reported in which the SILAC ratio is corrected for incomplete labeling by monitoring the label incorporation of every protein $(4,5)$. However, this strategy has several obvious disadvantages. First, each SILAC analysis requires a parallel analysis to measure the label incorporation for every single protein. In addition to the extra cost and effort, it is difficult to obtain the label incorporation for every protein because it requires the protein be quantified in two analyses. A considerable proportion of the SILAC protein ratios cannot be corrected because for analysis of complex protein mixtures by liquid chromatography tandem mass spectrometry (LC MS/MS), protein identification is typically only partially overlapped between replicate analyses (2).

Moreover, the correction step introduces additional variation that compromises the accuracy of quantitation.

To circumvent these problems, we employ a multiplex SILAC labeling strategy for primary neurons (Fig. 1) (6-8). Instead of using light and heavy labeling amino acids to distinguish the two experimental conditions, we use two different sets of heavy amino acids, $\mathrm{D}_{4}$ lysine $/{ }^{13} \mathrm{C}_{6}$-arginine (Lys4/Arg6) and ${ }^{13} \mathrm{C}_{6}{ }^{15} \mathrm{~N}_{2}$-lysine $/{ }^{13} \mathrm{C}_{6}{ }^{15} \mathrm{~N}_{4}$-arginine (Lys8/Arg 10 ). Because the two cell populations incorporate the two sets of amino acids at the same rate, they are always equally labeled. SILAC quantitation is done using the signals of the medium (Lys4/Arg6) and heavy (Lys8/Arg10) labeled peptides, and the unlabeled peptides can be ignored. This allows for straightforward and accurate SILAC quantitation using partially labeled cells.

Here we describe a protocol for SILAC culture of primary cortical neurons from embryonic rat brain.

\section{Materials}

\subsection{Equipment and Labware}

1. Horizontal laminar flow hood for dissections

2. Laminar flow biological hood for cell culture

3. Humidified culture incubator at $37^{\circ} \mathrm{C}$ and $5 \% \mathrm{CO}_{2}$

4. Dissecting microscope

5. Dissecting tools (we use scissors and Dumont \#5 and \#5/45 forceps from Fine Science Tools)

6. Centrifuge to accommodate $15 \mathrm{ml}$ tubes

7. Vacuum-driven filter units $(0.45 \mu \mathrm{m}$ pore size, $250 \mathrm{ml})$

8. Water bath $37^{\circ} \mathrm{C}$

9. $70 \mu \mathrm{m}$ cell strainers 
10. $10 \mathrm{~cm}$ and $6 \mathrm{~cm}$ sterile Petri dishes

11. Tissue culture dishes (size depends on number of cells in the experiment)

12. Glass Pasteur pipettes, fire-polished to three different pore sizes, each about $50 \%$ the size of the previous opening (approx. $1 \mathrm{~mm}, 0.5 \mathrm{~mm}$ and $0.2 \mathrm{~mm}$ in diameter)

13. Hemocytometer

\subsection{Animal and Reagents}

1. Timed-pregnant female (Sprague-Dawley) rat, embryonic day E18

2. Ca--Mg-free Hanks' balanced salt solution (HBSS)

3. Neurobasal medium

4. Neurobasal medium deficient of arginine and lysine (custom-made from Invitrogen)

5. B-27 supplement $50 \mathrm{x}$

6. 5-fluorouridine/uridine (5-FU; $10 \mathrm{mM}$ each as stock solution)

7. L- glutamine, $200 \mathrm{mM}$ stock

8. $\mathrm{D}_{4}$-lysine, ${ }^{13} \mathrm{C}_{6}$-arginine, ${ }^{13} \mathrm{C}_{6}{ }^{15} \mathrm{~N}_{2}$-lysine and ${ }^{13} \mathrm{C}_{6}{ }^{15} \mathrm{~N}_{4}$-arginine

9. Penicillin/streptomycin (5000 units of penicillin and $5000 \mu \mathrm{g}$ of streptomycin per $\mathrm{ml})$

10. $0.5 \%$ Trypsin-EDTA $(4.8 \mathrm{mM})$

11. Fetal bovine serum (FBS)

\subsection{SILAC Media and Other Solutions}

1. Coating solution: dissolve poly-D-lysine in cell culture water and dilute to 0.1 $\mathrm{mg} / \mathrm{ml}$. Filter with filter units $(0.45 \mu \mathrm{m})$.

2. Dissection solution: add glucose stock (37\%, sterile) to HBSS (1:100).

3. SILAC media: Prepare 1000x stock solutions for labeling amino acids: $398 \mathrm{mM}$ for arginines and $798 \mathrm{mM}$ for lysines (in water). Add B-27 supplement (1:50), Lglutamine (1:400) and penicillin/streptomycin (1:100) to neurobasal medium deficient of arginine and lysine. Split the medium equally into two parts. To half of the medium add the Arg6 and Lys4 stocks (1:1000). To the other half add the Arg10 and Lys8 stocks (1:1000). Filter both media using $0.45 \mu \mathrm{m}$ filter units. The SILAC media can be store at $4^{\circ} \mathrm{C}$ for up to four weeks.

\section{Methods}

It is important that all tissue culture steps be performed in a sterile environment. Therefore, dissections are carried out in a horizontal laminar flow hood, using a dissecting microscope. Tissue dissociation and cell culture are performed in a vertical flow hood. 


\subsection{Dissection}

1. In the vertical flow hood, coat culture plates with poly-D-lysine for at least $1 \mathrm{~h}$, then wash with water and let dry. Coated and dried plates can be stored at $4^{\circ} \mathrm{C}$ for a week or at $-20^{\circ} \mathrm{C}$ for a month.

2. Sacrifice pregnant female rat using $\mathrm{CO}_{2}$, followed by cervical dislocation. Remove uterus, place it into a $10 \mathrm{~cm}$ sterile Petri dish filled with dissection solution and move to horizontal flow hood.

3. Isolate E18 fetuses and collect them in fresh dissection solution. Make sure to rinse off remaining blood.

4. Isolate embryonic brains and place them into a $6 \mathrm{~cm}$ sterile Petri dish filled with dissection solution. Using a dissecting microscope, dissect out cortices and remove the meninges (see Notes 1 and ${ }^{2}$ ).

5. Collect isolated cortices in dissection solution and move to vertical flow hood.

6. Split cortices to collect 6-8 embryos worth of tissue per $15 \mathrm{ml}$ conical tube in $3 \mathrm{ml}$ of dissection solution. Add $300 \mu$ of trypsin-EDTA and incubate at $37^{\circ} \mathrm{C}$ for $8 \mathrm{~min}$ to disrupt cell-cell contacts (see Note 3).

7. Add $1 \mathrm{ml}$ of FBS to quench the trypsin and spin cells for $3 \mathrm{~min}$ at $300 \mathrm{x}$ g. Remove supernatant and resuspend cells in $1 \mathrm{ml}$ of regular neurobasal medium.

8. Triturate cells with fire-polished glass Pasteur pipettes, starting with the largest opening, followed by the medium and the smallest opening. Triturate about $6-8$ times with each pipette. This will dissociate tissue into a single cell suspension (see Notes 4 and ${ }^{5}$ ).

9. Pool all dissociated cells, filter through a cell strainer to remove non-dissociated larger chunks.

10. Count cells using a hemacytometer. Typical yields are $\sim 15$ million cells per embryo for cortical neurons.

\subsection{SILAC Cell Culture}

1. Suspend the cells well by pipetting and split equally into two $15 \mathrm{ml}$ tubes. Spin cells down for $3 \mathrm{~min}$ at $300 \mathrm{x}$ g. Carefully remove the supernatant.

2. Resuspend cells in SILAC media at required density.

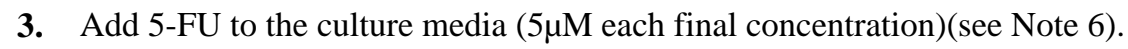

\footnotetext{
${ }^{1}$ This protocol describes the methods using rat embryonic cortical cultures. Other neuronal cultures, e.g. from genetically modified mice, can be used as required.

${ }^{2}$ During all steps, make sure the tissue is always submerged in dissection solution and thus does not dry.

${ }^{3}$ It is important that the tissue is not incubated in trypsin for more than $8-10 \mathrm{~min}$ as this leads to neuronal damage and reduces the health of the cultures.

${ }^{4}$ The diameter of the fire-polished Pasteur pipettes (see 2.1.12) is important, as too large a diameter will not efficiently dissociate the tissue, while too small a diameter can damage the cells.

$5 \mathrm{Be}$ careful to avoid excess bubble formation when triturating, as the increase in surface tension can rupture the cells. If tissue or cells start forming sticky clumps, add $10 \mu \mathrm{g} / \mathrm{ml}$ of DNase to the trituration, this should dissolve clumps.
} 
4. Plate cells in culture dishes (see Notes 7 and ${ }^{8}$ ).

5. Place cells in a humidified incubator at $37^{\circ} \mathrm{C}$ and $5 \% \mathrm{CO}_{2}$.

6. Check cells daily under a microscope. Make sure cells grow equally well in the two SILAC media (see Note 9).

7. Exchange half of the culture media for fresh media every three days. Add 5-FU to fresh media before each medium exchange (see Note 10).

8. Grow neurons for about 10 days before proceeding to cell treatment/lysis/MS analysis (see Notes $11{ }^{15}$ ).

\section{Acknowledgments}

This work was supported by NIH NINDS grant P30 NS050276 to TAN.

\section{References}

1. Ong SE, Blagoev B, Kratchmarova I, et al. Stable isotope labeling by amino acids in cell culture, SILAC, as a simple and accurate approach to expression proteomics. Mol Cell Proteomics. 2002; 1:376-386. [PubMed: 12118079]

2. Elias JE, Haas W, Faherty BK, et al. Comparative evaluation of mass spectrometry platforms used in large-scale proteomics investigations. Nat Methods. 2005; 2:667-675. [PubMed: 16118637]

3. Ong SE, Mann M. A practical recipe for stable isotope labeling by amino acids in cell culture (SILAC). Nat Protoc. 2006; 1:2650-2660. [PubMed: 17406521]

4. Spellman DS, Deinhardt K, Darie CC, et al. Stable isotopic labeling by amino acids in cultured primary neurons: application to brain-derived neurotrophic factor-dependent phosphotyrosineassociated signaling. Mol Cell Proteomics. 2008; 7:1067-1076. [PubMed: 18256212]

5. Liao L, Park SK, Xu T, et al. Quantitative proteomic analysis of primary neurons reveals diverse changes in synaptic protein content in fmr1 knockout mice. Proc Natl Acad Sci U S A. 2008; 105:15281-15286. [PubMed: 18829439]

6. Selbach M, Schwanhausser B, Thierfelder N, et al. Widespread changes in protein synthesis induced by microRNAs. Nature. 2008; 455:58-63. [PubMed: 18668040]

7. Zhang G, Deinhardt K, Chao MV, et al. Study of neurotrophin-3 signaling in primary cultured neurons using multiplex stable isotope labeling with amino acids in cell culture. J Proteome Res. 2011; 10:2546-2554. [PubMed: 21370927]

\footnotetext{
${ }^{6}$ Addition of 5-FU inhibits growth of dividing cells such as glia cells. Typically in our cultures less than $1 \%$ of the cell population is non-neuron cells.

${ }^{7}$ Many protocols require neurons be plated in medium containing FBS. However, we found that plating neurons in FBS-free medium does not affect cell survival as compared to FBS-containing medium.

${ }^{8}$ For SILAC experiments that require a lot of material, we plate cells at a density of up to 15 million $/ 10 \mathrm{~cm}$ culture dish. We found that at this density, cell growth is normal compared to lower densities and there is no need for more frequent medium change.

9It is critical to maintain equal growth between the two SILAC-labeled populations because unequal growth will cause differences in label incorporation levels in the two cell populations and eventually lead to errors in SILAC quantitation. To ensure this, make every

effort to handle the two cell populations in the same way as much as possible.

${ }^{10}$ Cultured neurons secrete growth factors that are important for growth and maintenance of neurons. Refreshing only half of the medium allows a certain amount of these growth factors to be retained.

${ }^{11}$ Label incorporation increases rapidly in the first several days and slows down after 6 or 7 days in culture. See Fig. 2 for an

illustration of label incorporation versus culture time.

${ }^{15}$ Arginine to proline conversion $(1,9)$ typically occurs in SILAC labeling of cortical neurons at a low level $(<5 \%)$. We have found that this does not significantly affect protein quantitation. However, occasionally high levels of conversion (>30\%) were observed for reasons that are not well understood. In such a case, the conversion can be inhibited by adding $300 \mathrm{mg} / \mathrm{L}$ L-proline into the SILAC culture medium. For other types of neurons, the conversion level may be different. We also caution that for quantitation of prolinecontaining peptides, the effect of this conversion on quantitation may be more pronounced (9).
} 
8. Zhang G, Neubert TA, Jordan BA. RNA binding proteins accumulate at the postsynaptic density with synaptic activity. J Neurosci. 2012; 32:599-609. [PubMed: 22238095]

9. Van Hoof D, Pinkse MW, Oostwaard DW, et al. An experimental correction for arginine-to-proline conversion artifacts in SILAC-based quantitative proteomics. Nat Methods. 2007; 4:677-678.

[PubMed: 17762871] 

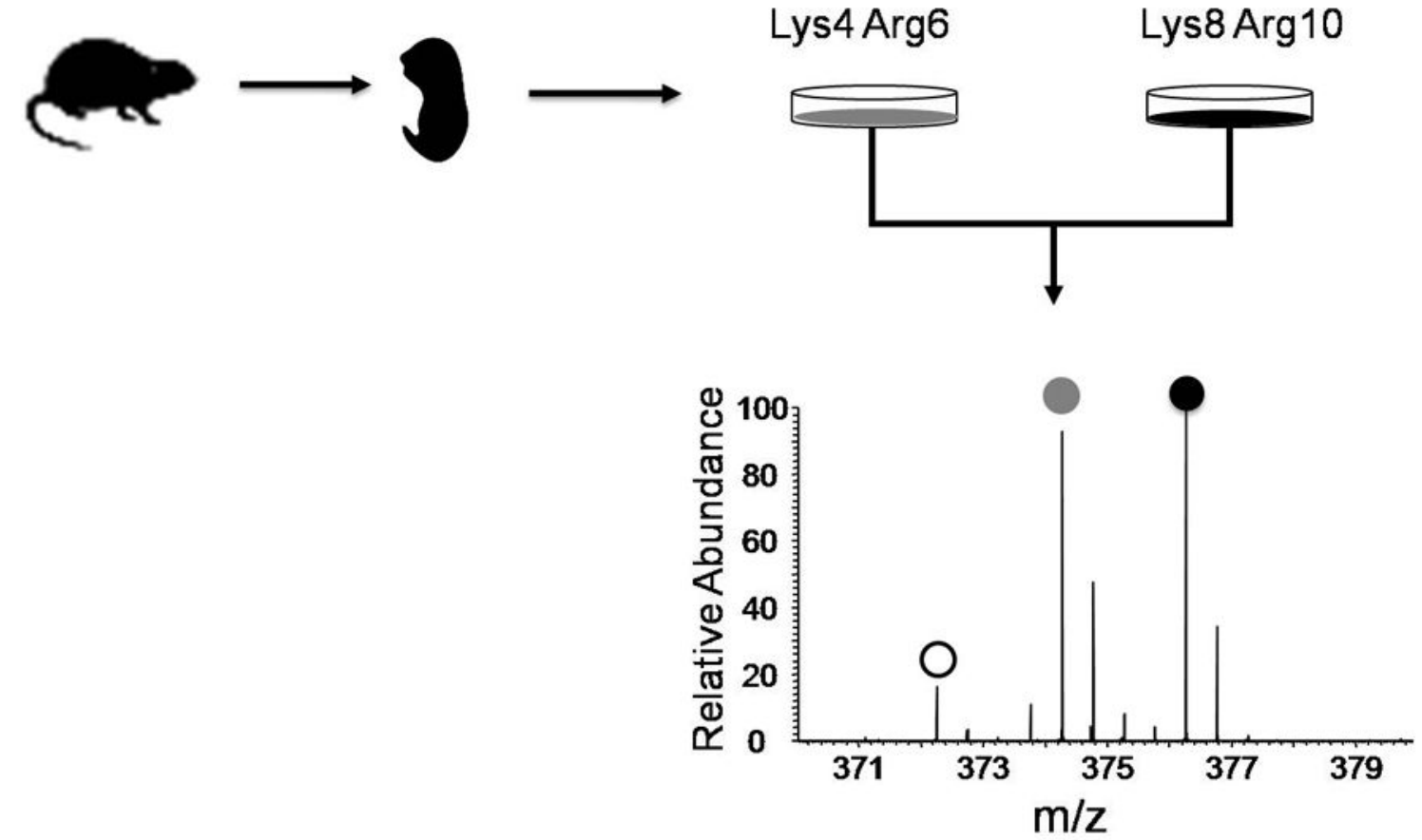

Fig. 1.

Schematic of multiplex SILAC labeling for primary cultured neurons. Two different versions of stable isotope-coded amino acids (medium and heavy, represented by gray and black colors, respectively) were used for labeling. This strategy does not require complete labeling because the medium and heavy amino acids are incorporated at the same rate. An MS spectrum of a representative peptide (LLASLVK from Trim 28) is shown as an example. (The gray and black circles denote the medium and heavy peptide signals, respectively, while the open circle denotes the light signal). The MS spectrum was acquired using an LTQ-Orbitrap mass spectrometer. 
After 2 days in culture

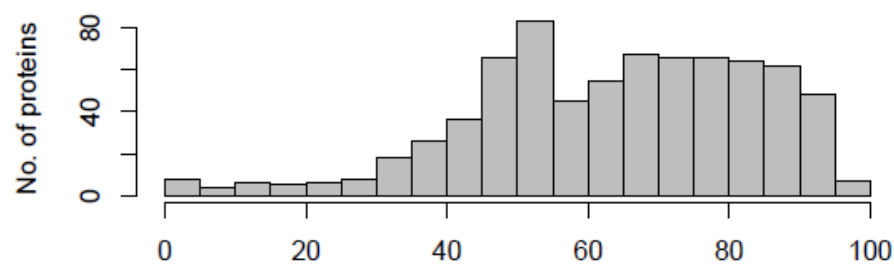

After 6 days in culture

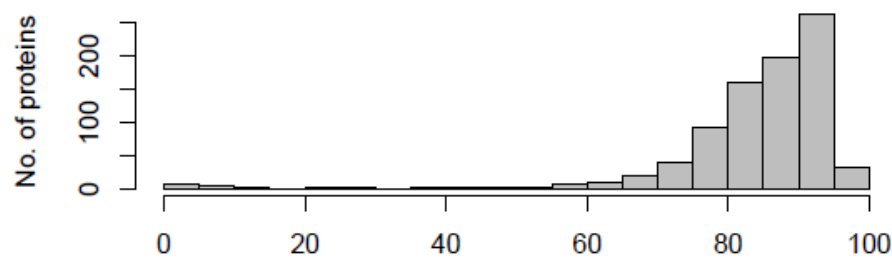

After 10 days in culture

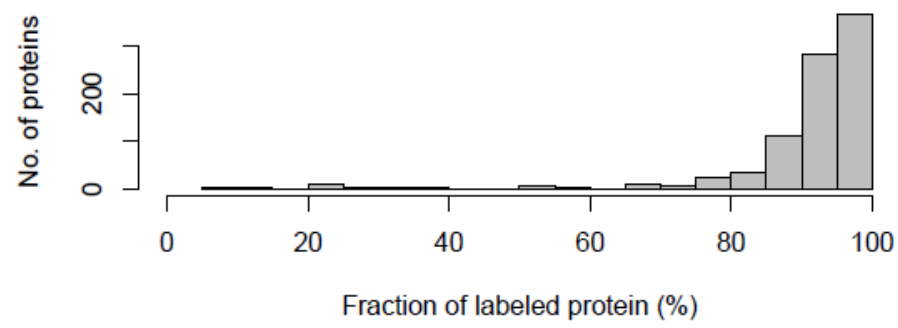

Fig. 2.

Label incorporation after SILAC labeling of primary cultured cortical neurons for 2, 6 and 10 days. The histograms are plotted based on 746, 844, and 862 quantified proteins from the 2, 6 and 10 day-neurons, respectively. The MS data were acquired using an LTQ-Orbitrap mass spectrometer (7). 